\title{
ARTICLE \\ A pharmacodynamic model of respiratory rate and end-tidal carbon dioxide values during anesthesia in children
}

\author{
Ji-Hyun Lee ${ }^{1}$, Pyo-Yoon Kang ${ }^{1}$, Young-Eun Jang ${ }^{1}$, Eun-Hee Kim ${ }^{1}$, Jin-Tae Kim ${ }^{2}$ and Hee-Soo Kim ${ }^{2}$
}

It is essential to monitor the end-tidal carbon dioxide $\left(\mathrm{ETCO}_{2}\right)$ during general anesthesia and adjust the tidal volume and respiratory rate (RR). For the purpose of this study, we used a population pharmacodynamic modeling approach to establish the relationship between $\mathrm{RR}$ versus $\mathrm{ETCO}_{2}$ data during general anesthesia in children, and to identify the clinical variables affecting this relationship. A prospective observational study was designed to include 51 patients (aged $\leq 12$ years), including users of antiepileptic drugs (levetiracetam, valproic, or phenobarbital $(n=21)$ ) and non-users $(n=30)$, scheduled to receive general anesthesia during elective surgery. When the $\mathrm{ETCO}_{2}$ was at $40 \mathrm{mmHg}$, the RR was adjusted 1 breath per every 2 min until the ETCO $\mathrm{Eas}_{2} 30 \mathrm{mmHg}$ and recovered to $40 \mathrm{mmHg}$. Pharmacodynamic analysis using a sigmoid $E_{\max }$ model was performed to assess the RR-ETCO $\mathrm{R}_{2}$ relationship. As RR varied from 3 to 37 breaths per minute, the $\mathrm{ETCO}_{2}$ changed from 40 to $30 \mathrm{mmHg}$. Hysteresis between the RR and ETCO $\mathrm{Cas}_{2}$

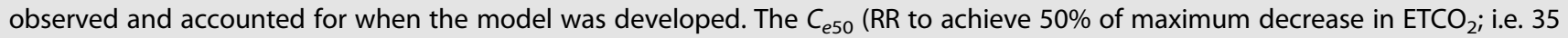
$\mathrm{mmHg}$ ) was 20.5 in non-users of antiepileptic drugs and 14.9 in those on antiepileptic drug medication. The values of $\gamma$ (the steepness of the concentration-response relation curve) and $k_{e o}$ (the first-order rate constant determining the equilibration between the RR and $\mathrm{ETCO}_{2}$ ) were 7.53 and $0.467 \mathrm{~min}^{-1}$, respectively. The $C_{e 50}$ and $\mathrm{ETCO}_{2}$ data fit to a sigmoid $E_{\text {max }}$ model. In conclusion, the RR required to get the target $\mathrm{ETCO}_{2}$ was much lower in children patients taking antiepileptic drugs than that of nonuser children patients during the general anesthesia.

Keywords: pediatric anesthesia; end-tidal carbon dioxide; respiratory rate; population pharmacodynamic modeling; antiepileptic drugs

Acta Pharmacologica Sinica (2019) 40:642-647; https://doi.org/10.1038/s41401-018-0156-x

\section{INTRODUCTION}

During general anesthesia, it is essential to control and monitor the ventilation status by using the respiratory rate (RR), tidal volume, end-tidal carbon dioxide $\left(\mathrm{ETCO}_{2}\right)$, and oxygenation.

Several studies have tried to find the optimal tidal volume during mechanical ventilation to protect the lung in various clinical situations [1, 2]. With the determined tidal volume, there is variation in the $\mathrm{RR}$ required to maintain normocarbia, regardless of the preoperative RR measured in the ward during the resting period, and it is relatively liberally controlled.

$\mathrm{ETCO}_{2}$ monitoring with capnography is a non-invasive and a useful surrogate parameter for the partial pressure of arterial carbon dioxide $\left(\mathrm{PaCO}_{2}\right)[3,4]$, despite its inaccuracies [5]. The $\mathrm{ETCO}_{2}$ monitor has been important because it can confirm an endotracheal intubation or ventilation, and can also be used to control the cerebral blood flow. Anesthesiologists have managed the cerebral blood flow with $\mathrm{ETCO}_{2}$, which is representative of the $\mathrm{PaCO}_{2}$ and has a great effect on the control of cerebral vessels.

Usually, the RR is adjusted based on the $\mathrm{ETCO}_{2}$ or $\mathrm{PaCO}_{2}$ to maintain the normocarbia, which reflects the minute ventilation. However, we have observed that patients with hydrocephalus or antiepileptic drugs show unexpectedly low $\mathrm{ETCO}_{2}$ levels compared to other pediatric patients with the determined tidal volume and $\mathrm{RR}$ in mechanical ventilation during general anesthesia. Therefore, it would be useful if we established a pharmacodynamic model that incorporates a population approach with covariates such as age, sex, history of medication, or clinical status to describe the minute ventilation $\mathrm{ETCO}_{2}$ doseresponse relationship.

In this study, we attempted to identify the clinical variables affecting the relationship between RR and $\mathrm{ETCO}_{2}$, and establish the population pharmacodynamic modeling approach to RR and $\mathrm{ETCO}_{2}$ data during general anesthesia in children.

\section{MATERIALS AND METHODS}

Patient recruitment and anesthetic methods

The study was approved by the Institutional Review Board of Seoul National University Hospital (1602-079-740) and registered at http://cris.nih.go.kr (КСT0001859). Each participant was given a verbal explanation and had the opportunity to ask questions about the study methods and purposes, and informed consent was acquired from one parent. Verbal consent was acquired from the participants. All procedures followed the principles of the Declaration of Helsinki and its revisions.

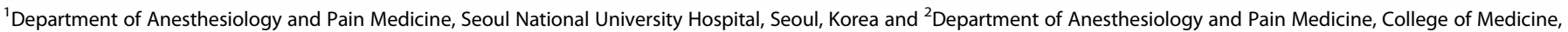
Seoul National University, Seoul, Korea

Correspondence: Hee-Soo Kim (dami0605@snu.ac.kr) 
A total of 56 patients (ages between 1 month and 6 years), who underwent surgery under general anesthesia and were or were not taking a chronic ( $>7$ days) antiepileptic drug, were enrolled in this study. The exclusion criteria were acutely increased intracranial pressure, moyamoya disease, or other conditions that could affect $\mathrm{PaCO}_{2}$.

All the patients complied with the preoperative fasting time according to the practice guidelines from the American Society of Anesthesiologists. All the recruited patients did not receive premedication. Standard monitoring, including electrocardiogram (ECG), heart rate $(\mathrm{HR})$, non-invasive blood pressure $(\mathrm{BP})$ in 1 -min intervals, peripheral oxygen saturation $\left(\mathrm{SpO}_{2}\right)$, and $\mathrm{ETCO}_{2}$ were monitored. Anesthesia was induced with thiopental sodium (5-6 $\mathrm{mg} / \mathrm{kg}$ under 3-year-old) or propofol (2-2.5 mg/kg over 3-yearold), and the patients were manually ventilated with a mixture of $8 \%$ (vol) sevoflurane and $100 \%$ oxygen. Rocuronium was administered to facilitate the endotracheal intubation. Anesthesia was maintained using 1 MAC of sevoflurane with a remifentanil infusion, and the inspired oxygen fraction was 0.4 . Tidal volume was $8 \mathrm{~mL} / \mathrm{kg}$. The initial RR was controlled to a goal $\mathrm{ETCO}_{2}$ of 40 $\mathrm{mmHg}$. An esophageal stethoscope was inserted to monitor the temperature. Body temperature was maintained over $35.5{ }^{\circ} \mathrm{C}$ during the study period.

\section{Study protocol}

After the stabilization of $\mathrm{ETCO}_{2}$ at $40 \mathrm{mmHg}$ for $10 \mathrm{~min}$ after the start of surgery, RR was increased stepwise by 1 breath every $2 \mathrm{~min}$, down to a minimal $\mathrm{ETCO}_{2}$ of $30 \mathrm{mmHg}$, with a fixed tidal volume. Subsequently, the RR was decreased stepwise by 1 breath per every $2 \mathrm{~min}$, up to an $\mathrm{ETCO}_{2}$ of $40 \mathrm{mmHg}$. During the study period, all the vital signs (ECG, $\mathrm{HR}, \mathrm{BP}, \mathrm{SpO}_{2}$, and temperature) were closely monitored. After the study period, attending anesthesiologists liberally adjusted the RR to maintain an $\mathrm{ETCO}_{2}$ between 30 and $40 \mathrm{mmHg}$.

Data analysis and model selection

The RR and corresponding $\mathrm{ETCO}_{2}$ data with demographic characteristics were used to develop a pharmacodynamic model with NONMEM (nonlinear mixed-effects modeling) software (ver VII; GloboMax, Hanover, MD, USA). The model provides estimates of the population's mean parameters, inter-individual random variabilities, and residual random effects. The pharmacodynamic model was run using the first-order conditional estimation method with inter-individual-residual interaction (FOCEI) to determine parameter estimates. To account for the delay between RR measurements and the $\mathrm{ETCO}_{2}$ at the effect site (lung), an effect compartment $\left(C_{\mathrm{e}}\right)$ was modeled. It was assumed that RR was linearly linked to $C_{e}$, which was estimated by the following equation:

$\mathrm{d} C_{\mathrm{e}} / \mathrm{d} t=\left(\mathrm{RR}-C_{\mathrm{e}}\right) \times k_{\mathrm{e} 0}$,

where $k_{\mathrm{e} 0}$ is the first-order rate constant determining the equilibration between the RR and $\mathrm{ETCO}_{2}$. The $C_{e}$ over time was calculated as the convolution of the RR over time with the disposition function of the effect site. The convolution was based on a "connect-the-dots" approach previously used by Schnider et al. [6]. The $k_{\mathrm{e} 0}$ was estimated by minimizing the area of the hysteresis loop of the $\mathrm{ETCO}_{2}$ data versus the RR. One individual $k_{\mathrm{e} 0}$ value was calculated for each patient on the basis of his or her particular respiratory ramp. The relationship between $\mathrm{RR}$ and $\mathrm{ETCO}_{2}$ was modeled using a sigmoid $E_{\max }$ model:

$E_{\max }$ model : $E=E_{0}+\left(E_{\max }-E_{0}\right) \times C_{\mathrm{e}}^{\lambda} /\left(C_{\mathrm{e} 50}^{\lambda}+C_{\mathrm{e}}^{\lambda}\right)$,

where $E_{0}$ is the initial $\mathrm{ETCO}_{2}=40 \mathrm{mmHg}, E_{\max }$ is the $\mathrm{ETCO}_{2}=$ $30 \mathrm{mmHg}, C_{\mathrm{e} 50}$ is the RR required to get $50 \%$ of maximum decrement of $\mathrm{ETCO}_{2}$ ( $35 \mathrm{mmHg}$ of $\mathrm{ETCO}_{2}$ in this study), and $\gamma$ is the steepness of the concentration-response relation curve. Interindividual variability in $E_{0}, E_{\mathrm{max}}, C_{\mathrm{e} 50}, \gamma$, and $k_{\mathrm{e} 0}$ was modeled using an exponential error model. Residual intra-individual variability was modeled using the additive error model. NONMEM computed the minimum objective function value (OFV), a statistical equivalent to the -2 log-likelihood of the model. A level of 0.05 , which corresponds to a reduction in the OFV of 3.84 (chi-square distribution, degrees of freedom $=1, P<0.05$ ), was used to distinguish between the hierarchical models. First, we developed the basic population model without the covariates. Then, we explored additional covariates of sex, age, height, weight, and group (according to the history of antiepileptic drug medication) successively to determine their impact on estimates of the model parameters. The control code for developing of model was shown in Appedix 1. Bootstrap analysis internally validated the models (fit4NM 4.6.0, Eun-Kyung Lee and Gyu-Jeong Noh; http://fit4NM.org) [7]. Predictive checks were performed using fit4NM 4.6.0 [7].

Statistical analysis

Statistical analyses were performed using SPSS 23.0 for Windows (SPSS Inc., Chicago, IL, USA). Data are expressed as the mean \pm standard deviation for normally distributed continuous variables, the median [IQ: $25-75 \%$ ] for non-normally distribute continuous variables, and counts and percentages for categorical variables.

\section{RESULTS}

Demographic data are shown in Table 1. A total of 56 patients were recruited, and 51 completed the study. Data for five individuals in the antiepileptic drug group were excluded because of a surgery time that was too short to get data. Fifteen children took levetiracetam, two took valproic acid, one took phenobarbital, and three used combination therapy.

During the study period, there were no hypertension, hypotension, bradycardia, tachycardia, or desaturation events. RR was adjusted by 1 breath every 2 min. $\mathrm{ETCO}_{2}$ was changed later compared to the changes in RR, and this showed hysteresis. As a result, although RR was decreased to increase the $\mathrm{ETCO}_{2}$, after an $\mathrm{ETCO}_{2}$ of $30 \mathrm{mmHg}$ was achieved, $\mathrm{ETCO}_{2}$ decreased more to less than $30 \mathrm{mmHg}$. Therefore, the lowest $\mathrm{ETCO}_{2}$ was $28 \mathrm{mmHg}$. Then, the reverse process was imposed. RR was quite variable and ranged from 3 to 37 breaths per minute. The time to reach the minimal $\mathrm{ETCO}_{2}$ was compared in each group, and there was no significant difference between the two groups (20.0 [10.0-22] vs. 19.26 [14-24] $\min , P=0.708)$.

Figure 1 shows the time course of the RR and the changes in $\mathrm{ETCO}_{2}$ in all the recruited patients. An increased RR was matched with a decreased $\mathrm{ETCO}_{2}$. Figure 2 shows the plot of RR versus

Table 1. Demographic characteristics

\begin{tabular}{llll}
\hline & Normal $(n=30)$ & Antiepileptic drug $(n=21)$ & $P$-value \\
\hline M/F & $19 / 11$ & $13 / 8$ & \\
Age (year) & $2.2[0.77-3.0]$ & $2.4[0.60-5.0]$ & 0.807 \\
Height (cm) & $89.2[74.2-98.0]$ & $85.5[63.0-105.5]$ & 0.711 \\
Weight $(\mathrm{kg})$ & $14.0[9.7-16.7]$ & $14.4[8.0-20.0]$ & 0.977 \\
Diagnosis & & Hydrocephalus (12) & \\
& & Intractable seizure (3) & \\
& & Cerebral palsy (1) & \\
& & Brain tumor (3) \\
& & Others (2) & \\
& & & \\
& &
\end{tabular}



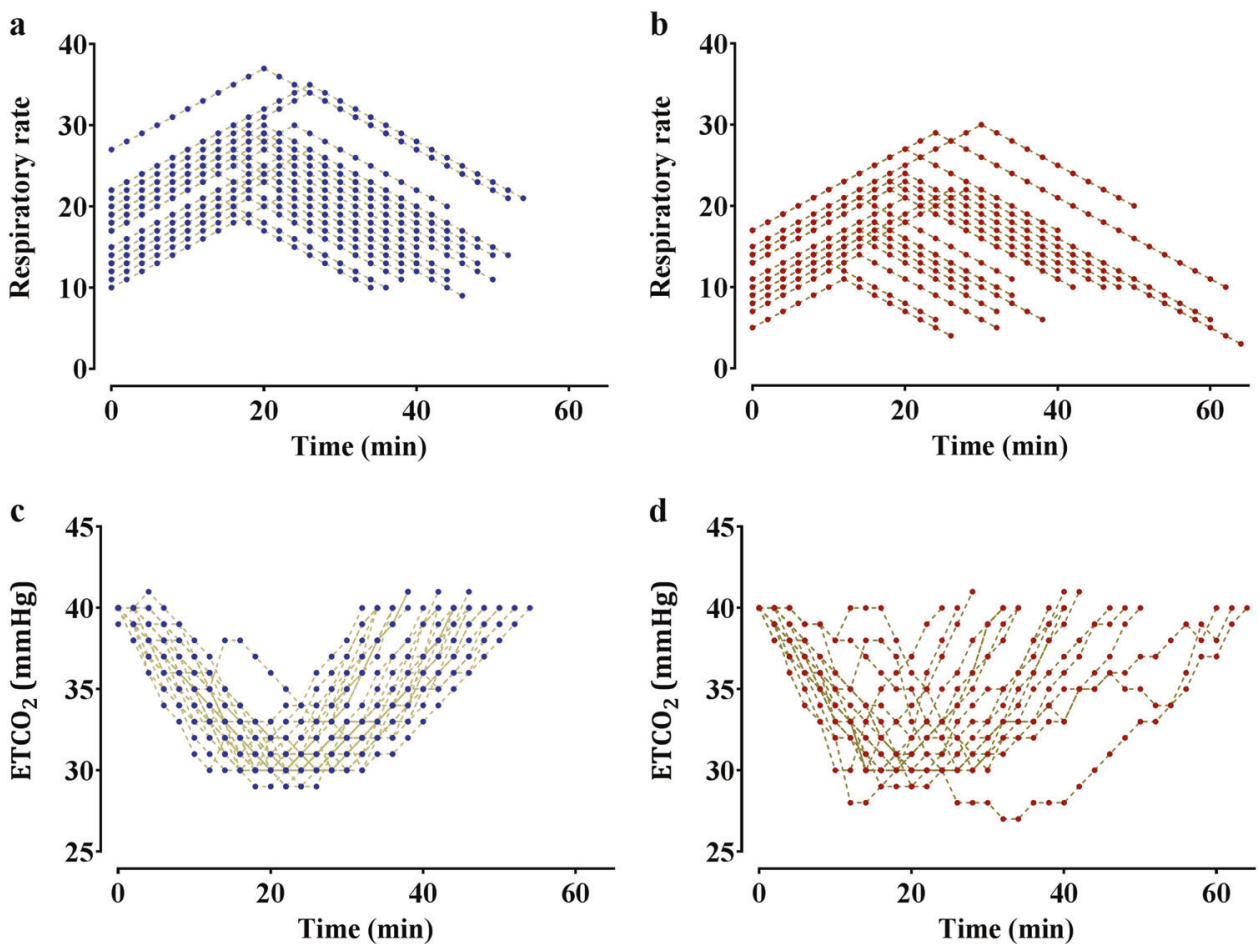

Fig. 1 Time courses of respiratory rate $(\mathrm{RR}, \mathbf{a})$ and end-tidal carbon dioxide $\left(\mathrm{ETCO}_{2}\right.$, b) during mechanical ventilation under general anesthesia in all recruited patients. Although the initial $\mathrm{ETCO}_{2}$ was set to $40 \mathrm{mmHg}$ and the minimal target $\mathrm{ETCO}_{2}$ was $30 \mathrm{mmHg}$, the minimal target $\mathrm{ETCO}_{2}$ was less than $30 \mathrm{mmHg}$ because of hysteresis between RR and $\mathrm{ETCO}_{2}$

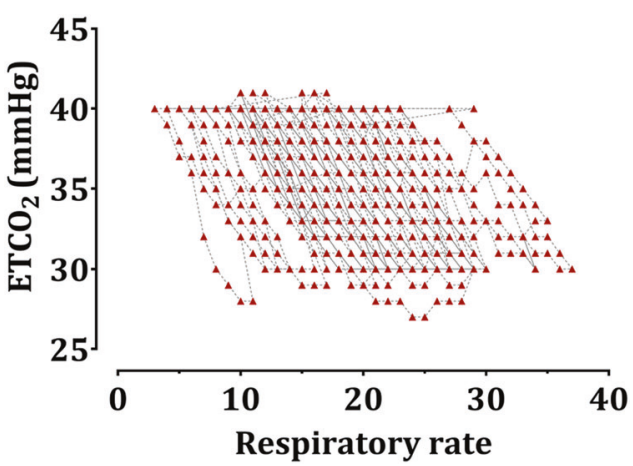

Fig. 2 The relationship between respiratory rate (RR) and end-tidal carbon dioxide $\left(\mathrm{ETCO}_{2}\right)$ during mechanical ventilation under general anesthesia in all recruited patients

$\mathrm{ETCO}_{2}$ in time. As the RR increased, the $\mathrm{ETCO}_{2}$ decreased, as expected.

For the development of the model, the total measurement of 1108 pairs of $\mathrm{ETCO}_{2}$ and RR were used. Antiepileptic drug medication history was a significant covariate for the $C_{\mathrm{e} 50}$, and it resulted in a greater improvement in the OFV $(\Delta 17.8, P<0.05$, degree of freedom $=1$ ) than the basic model.

The $C_{e 50}$ (20.5 vs. 14.9) differed between children who were users and non-users of antiepileptic drugs. The RR during $1 \mathrm{~min}$ that was needed to get an $\mathrm{ETCO}_{2}=35 \mathrm{mmHg}(50 \%$ reduction of highest $\mathrm{ETCO}_{2}$ [40 mmHg] to lowest $\mathrm{ETCO}_{2}[30 \mathrm{mmHg}]$ ) in the patients taking an antiepileptic drug was approximately five less than non-users. Other demographic parameters, such as age, sex, height, and weight were not assumed as covariates. The estimates of all parameters for the sigmoid $E_{\max }$ model are summarized in Table 2. Diagnostic plots (goodness-of-fit plots) for the final model are shown in Fig. 3, which shows that the model had a satisfactory performance and no significant bias. Predictive checks of the final model are presented in Fig. 4. In total, only $1.0 \%$ of the data were distributed outside of the $95 \%$ prediction intervals of the predictive check.

\section{DISCUSSION}

To our knowledge, this study was the first to apply the pharmacodynamic model to describe the effect of RR on $\mathrm{ETCO}_{2}$ in mechanical ventilation under general anesthesia in children. This study showed that the RR required to change the $\mathrm{ETCO}_{2}$ from $40 \mathrm{mmHg}$ to $35 \mathrm{mmHg}$ was lower in patients taking antiepileptic drugs compared to those who were not. This result was in line with the clinical findings.

To develop the pharmacodynamic model, first, we created the basic model and then added covariates such as age, sex, height, weight, and history of antiepileptic drugs for the final model. We fixed the initial and maximal reduced $\mathrm{ETCO}_{2}$ because those values are the clinically acceptable range $\left(30-40 \mathrm{mmHg}\right.$ of $\mathrm{ETCO}_{2}$ ). Therefore, $E_{\max }$ or $E_{0}$ could not be different between the two groups. There was a hysteresis between RR and $\mathrm{ETCO}_{2}$; there were several cases that were either over or less than the target ranges of $\mathrm{ETCO}_{2}$. Only $C_{\mathrm{e} 50}, \gamma$, and $k_{\mathrm{e} 0}$ were different between the two groups. During the development of the final model, adding the covariates and history of taking antiepileptic drugs reduced the OFV more than the basic model; there was a difference in $C_{\mathrm{e} 50}$ between the two different clinical situations (Table 2). Age, sex, height, or weight did not reduce the OFV.

$\mathrm{ETCO}_{2}$ is a useful and accurate parameter for estimating the $\mathrm{PaCO}_{2}$ in mechanically ventilated patients [4]. During general anesthesia, the minute ventilation was usually adjusted by changing the RR with a fixed tidal volume; $\mathrm{ETCO}_{2}$ is a guideline used to adjust the RR. Usually, the initial RR was set to the RR while the patient was on the ward or empirically with a fixed tidal 
Effect of antiepileptic drugs on respiratory rate and $\mathrm{ETCO}_{2}$

$\mathrm{JH}$ Lee et al.

\begin{tabular}{|c|c|c|c|c|}
\hline & Base model & Final model & & Median $[2.5-97.5 \%]$ \\
\hline$E_{0}, \mathrm{mmHg}$ & $39.8(0.16)$ & $39.8(0.15)$ & & 39.8 [39.7-39.9] \\
\hline$E_{\max }, \mathrm{mmHg}$ & $28.1(0.87)$ & $28.1(0.92)$ & & $28.1[27.8-28.4]$ \\
\hline$C_{\mathrm{e} 50}$, time $^{-1}$ & $18.1(3.92))$ & Normal & $20.5(3.48)$ & $20.3[19.3-21.4]$ \\
\hline$\gamma$ & $7.6(5.30)$ & $7.53(5.35)$ & & $7.6[7.2-8.1]$ \\
\hline$k_{\mathrm{eo}}, \min ^{-1}$ & $0.47(8.58)$ & $0.47(8.60)$ & & $0.47[0.42-0.52]$ \\
\hline OFV & 1138.8 & $1121.0(\Delta 17.8)$ & & \\
\hline
\end{tabular}
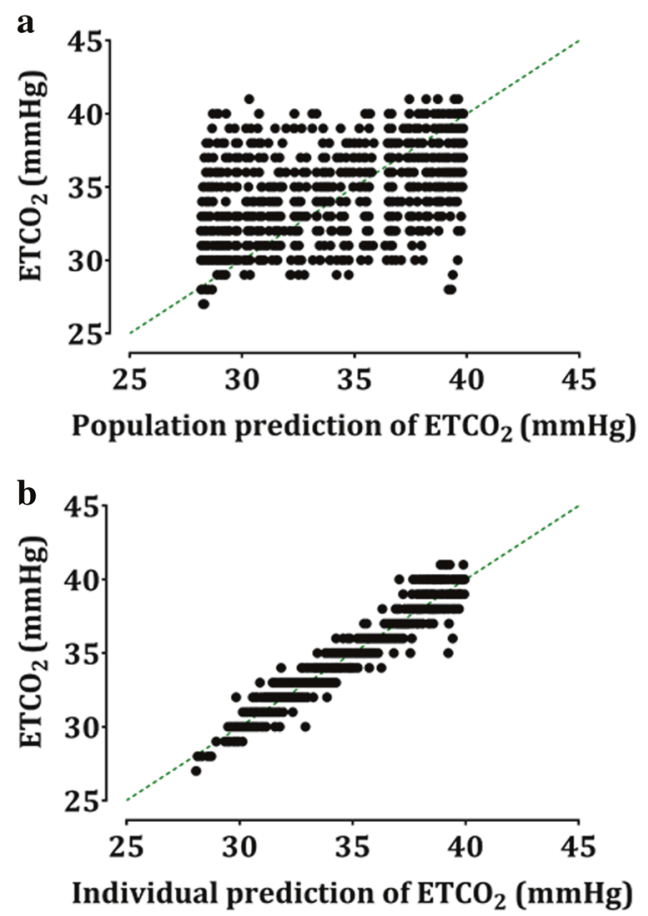

Fig. 3 Goodness-of-fit of the population (a) and individual prediction (b) of endo-tidal carbon dioxide of the final model. Dotted line represents the line of identity

volume $(8 \mathrm{~mL} / \mathrm{kg}$ in this study), and then gradually changed to maintain normocarbia, hypocarbia, or hypercarbia according to the clinical situation. There was a reference for RR during sleep based on age [8]. Considering the recruited patients in this study were aged from 3 months to 6 years, the ranges of the median RR were 20 to 29 breaths per minute; this was compatible with the observations of this study. The ranges of RR during anesthesia were 3 to 37 breaths per minute to maintain the $\mathrm{ETCO}_{2}$ between 30 and $40 \mathrm{mmHg}$. The lowest RR matched with $40 \mathrm{mmHg}$ of ETCO was seen in a 9-month-old boy taking an antiepileptic drug; the highest RR required to achieve an $\mathrm{ETCO}_{2}$ of $30 \mathrm{mmHg}$ was in a 10-month-old boy who was not taking any antiepileptic drugs.

Overall, the RR in patients taking antiepileptic drugs was definitely lower than that of non-users with the same age and similar weight to get the desired $\mathrm{ETCO}_{2}$. From the results of this study, we conclude that the increment of RR required to get halfway between the highest and lowest $\mathrm{ETCO}_{2}$ in a patient

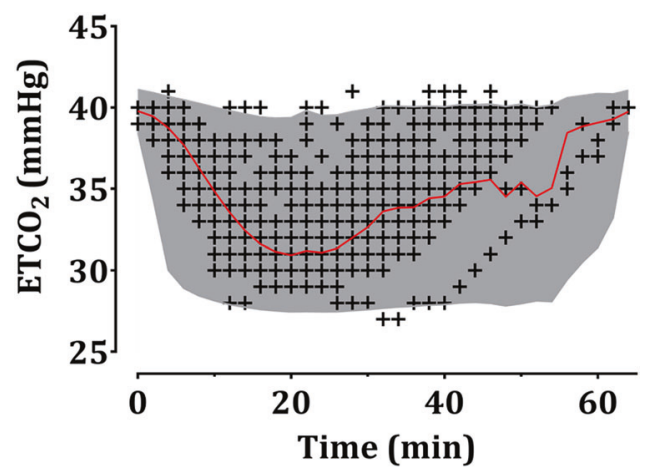

Fig. 4 Predictive checks of the final pharmacodynamic model. A black + indicates the observed end-tidal carbon dioxide $\left(\mathrm{ETCO}_{2}\right)$. The solid red line and shaded areas indicate the $50 \%$ prediction line and $95 \%$ prediction intervals, respectively. Baseline $\mathrm{ETCO}_{2}$ was set to $40 \mathrm{mmHg}$. The time shows the total study period needed for changing $\mathrm{ETCO}_{2}(40-30-40 \mathrm{mmHg})$

taking antiepileptic drugs was less than that of a non-user. This finding was compatible with a previous clinical observation, and our newly developed pharmacodynamic model could explain this finding.

There are several categories of current antiepileptic drugs based on the foremost targets at their therapeutic concentrations. The suggested target and mechanisms are as follows: $\mathrm{Na}^{+}$channel [9], $\mathrm{Ca}^{2+}$ channel [10], $\mathrm{K}^{+}$channel [11], GABA-related actions [12], or synaptic vesicle protein $2 \mathrm{~A}$ [13]. Meanwhile, the mechanisms of action of volatile anesthetics are not fully known yet. Several hypotheses, such as the involvement of the GABA receptor [14], NMDA receptor [15], $\mathrm{Ca}^{2+}$ channel [16], protein kinase $C$ [17], $\mathrm{Na}^{+}$ channel [18], and $\mathrm{K}^{+}$channel [19] have been suggested. Therefore, the many targets of antiepileptic drugs overlap with the targets of volatile anesthetics. If antiepileptic drugs and volatile anesthetics are used together, inhibition of excitatory activity or exaggeration of inhibitory activity of the targets of the two drugs might show an additive or synergic effect. Therefore, in this study, the combined use of volatile aesthetic and antiepileptic drugs could generally inhibit or suppress the neuronal activity and result in reduced metabolism. As a result, $\mathrm{CO}_{2}$ production, which is a waste product of metabolism, could be reduced with coadministration of volatile anesthetics and antiepileptic drugs.

Most of the anesthetics, including sevoflurane, reduced regional cerebral blood flow and oxygen consumption. Therefore, the metabolic rate was reduced [20]. In addition, a hyper-excitable state of neurons in epilepsy has been shown, and the neurons are fueled by glucose, which results in a hypermetabolic state [21]. 
Therefore, antiepileptic drugs work by reducing the brain activities and the resulting brain metabolism. Under general anesthesia, brain activities are decreased, and with the antiepileptic drugs, these activities might be profoundly decreased and result in a reduced $\mathrm{CO}_{2}$ production because $\mathrm{CO}_{2}$ is the waste product of metabolism. Therefore, we hypothesize that the patient taking an antiepileptic drug under general anesthesia would have a suppression of brain metabolism and reduction of $\mathrm{CO}_{2}$ production. This assumption could be explained by the lower RR needed in the patients taking antiepileptic drugs to get the same $\mathrm{ETCO}_{2}$ compared to non-users with a fixed tidal volume.

Many studies have tried to determine the optimal tidal volume, but few studies have determined the optimal RR because of relative liberal control. In adults, RR did not vary much during the mechanical ventilation under general anesthesia. RR might not be the most important respiratory parameter in general anesthesia, especially in adults. However, RR is one of the relatively important respiratory parameters used to control the minute ventilation in children because they are developing and have a variety of RRs, and the results of this study may be important to pediatric anesthesiologists. Basically, anesthesiologists adjust the RR with a fixed tidal volume using a target $\mathrm{ETCO}_{2}$ [22]. Therefore, the calculated RR might be important for the target $\mathrm{ETCO}_{2}$, and the result of this study should help explain why.

There were several limitations to this study. First, we did not distinguish the antiepileptic drugs according to the antiepileptic drug categories. However, all the antiepileptic drugs have basically shown similar effects on the brain, and the results from patients using different categories of antiepileptic drugs might not be different. Next, we changed the RR every 2 min; this duration is relatively short, and the results obtained do not show a clean stepwise change in $\mathrm{ETCO}_{2}$. Furthermore, this does not reflect the real clinical practice. Although it does not mimic a real clinical situation, the model could provide a difference between the two groups, and this result would help notify pediatric anesthesiologists to change the RR to adjust the $\mathrm{ETCO}_{2}$ during general anesthesia.

In conclusion, the adjusted RR needed to set the $\mathrm{ETCO}_{2}$ between 40 and $35 \mathrm{mmHg}$ was much lesser in patients taking antiepileptic drugs compared to patients not taking antiepileptic drugs while on mechanical ventilation under general anesthesia.

\section{AUTHOR CONTRIBUTIONS}

JHL and HSK designed the study; JHL, EHK, YEJ, and JTK conducted the study and collected data; JHL and HSK analyzed the data; PYK, JHL, and HSK wrote the paper; and all authors revised the paper. Population pharmacodynamic modeling reveals the impact of antiepileptic drugs on the relationship between RR and $E T C \mathrm{O}_{2}$ values during general anesthesia in children.

\section{ADDITIONAL INFORMATION}

Competing interests: The authors declare no competing interests.

\footnotetext{
APPENDIX 1

\$PRED

$\mathrm{TH} 1=\mathrm{THETA}(1)$

$\mathrm{TH} 2=\mathrm{THETA}(2)$

$\mathrm{TH} 3=\mathrm{THETA}(3)$

$\mathrm{TH} 4=\mathrm{THETA}(4)$

$\mathrm{TH} 5=\mathrm{THETA}(5)$
}

NONMEM control code

\$PROB RUN\# 60101 (Direct PD fit for RR vs $\mathrm{CO}_{2}$ )

\$DATA AED_2.csV IGNORE =\#

\$INPUT ID TIME CP DV GROUP SEX AGE HT WT; TIME: min; CP: respiratory rate; DV: end-tidal $\mathrm{CO}_{2}$; Group: $0=$ normal group, $1=$ antiepileptic group; SEX: $0=$ male, $1=$ female; AGE: yr; HT: cm; WT: kg
$\mathrm{TH} 6=\mathrm{THETA}(6)$

$\mathrm{E} 0=\mathrm{TH} 1{ }^{*} \operatorname{EXP}(\operatorname{ETA}(1))$

$\mathrm{EMAX}=\mathrm{TH} 2^{*} \operatorname{EXP}(\mathrm{ETA}(2))$

$\mathrm{CE} 50=\left(\mathrm{TH}^{*}{ }^{*} \mathrm{GROUP}+\mathrm{TH} 6 *(1-\mathrm{GROUP})\right)^{*} \mathrm{EXP}(\mathrm{ETA}(3))$

$\mathrm{GAM}=\mathrm{TH} 4{ }^{*} \mathrm{EXP}(\mathrm{ETA}(4))$

$\mathrm{KEO}=\mathrm{TH}^{*} \mathrm{EXP}(\mathrm{ETA}(5))$

IF (TIME.EQ.0.OR.CP.EQ.0) THEN

$\mathrm{CE}=0$

$\mathrm{PTIME}=0$

$P C P=0$

$P C E=0$

ENDIF

DT = TIME-PTIME

IF (DT.EQ.0.OR.CP.EQ.0) THEN

DT1 $=1$

ELSE

$\mathrm{DT} 1=\mathrm{DT}$

ENDIF

IF(CP.GT.O.AND.CP.GE.PCP) THEN

SLOPE $=(C P-P C P) / D T 1$

$\mathrm{DELT}=\mathrm{DT} 1{ }^{*} \mathrm{SLOPE}+\left(\mathrm{KE}{ }^{*} \mathrm{PCP}-\mathrm{SLOPE}\right) *(1-\mathrm{EXP}(-\mathrm{KE} 0 * \mathrm{DT} 1)) / \mathrm{KE} 0$

ENDIF

IF(CP.GT.O.AND.CP.LT.PCP) THEN

$\mathrm{SLOPE}=(\mathrm{LOG}(\mathrm{CP})-\mathrm{LOG}(\mathrm{PCP})) / \mathrm{DT} 1$

$\mathrm{DELT}=\mathrm{PCP}{ }^{*} \mathrm{KEO} /(\mathrm{KEO}+\mathrm{SLOPE})^{*}\left(\mathrm{EXP}\left(\mathrm{DT} 1{ }^{*} \mathrm{SLOPE}\right)-\mathrm{EXP}\left(-\mathrm{KE} 0{ }^{*} \mathrm{DT} 1\right)\right)$

ENDIF

IF (CP.GT.O.AND.DT.GT.0) THEN

$C E=P C E^{*} E X P\left(-K E 0^{*} D T\right)+D E L T$

ELSE

$C E=P C E$

ENDIF

IPRED $=\mathrm{E} 0+(\mathrm{EMAX}-\mathrm{E} 0)^{*} \mathrm{CE}{ }^{* *} \mathrm{GAM} /\left(\mathrm{CE}{ }^{* *} \mathrm{GAM}+\mathrm{CE} 50^{* *} \mathrm{GAM}\right)$

PTIME $=$ TIME

$\mathrm{PCP}=\mathrm{CP}$

$\mathrm{PCE}=\mathrm{CE}$

$\mathrm{W}=1$

IRES $=$ DV - IPRED

IWRES $=$ IRES $/ \mathrm{W}$

$\mathrm{Y}=$ IPRED $+\mathrm{W}^{*} \mathrm{EPS}(1)$

\$THETA; \#6

$(20,40)$; EO

$(10,30)$; EMAx

$(1,15)$; CE50_antiepileptic group

$(1,3)$; GAM

$(0,0.1)$; KEO

$(1,15)$; CE50_normal group

\$OMEGA; 5

0.2; IIV_E0

0.2 ; IIV_EMAX

0.2 ; IIV_CE50

$0.2 ;$ IIV GAM

0.2 ; IIV_KEO

\$SIGMA;\#1

16; EPS

SESTIMATION NOTBT NOOBT NOSBT SIGL $=3$ NSIG $=1$ MAXEVAL $=9999$ PRINT $=5$ $M E T H O D=1$ INTER MSFO $=60101 . M S F$ NOABORT

$\$$ COVARIANCE PRINT $=E$

\$TABLE ID ETA(1) ETA(2) ETA(3) ETA(4) ETA(5)

FILE $=60101 . E T A$ NOPRINT FIRSTONLY NOAPPEND

\$TABLE ID EO EMAX CE50 GAM KEO

FILE $=$ 60101.PAR NOPRINT ONEHEADER NOAPPEND

\$TABLE ID TIME GROUP IPRED IWRES CWRES

FILE $=$ sdtab60101 NOPRINT ONEHEADER

\$TABLE ID E0 EMAX CE50 GAM KE0 ETA(1) ETA(2) ETA(3) ETA(4) ETA(5)

FILE $=$ patab60101 NOPRINT ONEHEADER NOAPPEND

\$TABLE ID AGE HT WT

FILE $=$ cotab60101 NOPRINT ONEHEADER NOAPPEND

\$TABLE ID SEX GROUP

FILE $=$ catab60101 NOPRINT ONEHEADER NOAPPEND

\section{REFERENCES}

1. Pi X, Cui Y, Wang C, Guo L, Sun B, Shi J, et al. Low tidal volume with PEEP and recruitment expedite the recovery of pulmonary function. Int J Clin Exp Pathol. 2015;8:14305-14. 
2. Xie P, Li Z, Tian Z. The optimal combination of mechanical ventilator parameters under general anesthesia in obese patients undergoing laparoscopic surgery. J Clin Anesth. 2016;34:290-4.

3. Bhavani-Shankar K, Moseley H, Kumar AY, Delph Y. Capnometry and anaesthesia. Can J Anaesth. 1992;39:617-32.

4. Razi E, Moosavi GA, Omidi K, Khakpour Saebi A, Razi A. Correlation of end-tidal carbon dioxide with arterial carbon dioxide in mechanically ventilated patients. Arch Trauma Res. 2012;1:58-62.

5. Onodi C, Buhler PK, Thomas J, Schmitz A, Weiss M. Arterial to end-tidal carbon dioxide difference in children undergoing mechanical ventilation of the lungs during general anaesthesia. Anaesthesia. 2017;72:1357-64.

6. Schnider TW, Minto CF, Shafer SL, Gambus PL, Andresen C, Goodale DB, et al. The influence of age on propofol pharmacodynamics. Anesthesiology. 1999;90:1502-16.

7. Ki SH, Rhim JH, Park JH, Han YJ, Cho YP, Kwon TW, et al. Quantitative analysis of the effect of end-tidal carbon dioxide on regional cerebral oxygen saturation in patients undergoing carotid endarterectomy under general anaesthesia. Br J Clin Pharmacol. 2018;84:292-300.

8. Ross KR, Rosen CL. Sleep and respiratory physiology in children. Clin Chest Med. 2014:35:457-67.

9. Boiteux C, Vorobyov I, French RJ, French C, Yarov-Yarovoy V, Allen TW. Local anesthetic and antiepileptic drug access and binding to a bacterial voltage-gated sodium channel. Proc Natl Acad Sci USA. 2014;111:13057-62.

10. Zamponi GW. Targeting voltage-gated calcium channels in neurological and psychiatric diseases. Nat Rev Drug Discov. 2016:15:19-34.

11. Leo A, Citraro R, Constanti A, De Sarro G, Russo E. Are big potassium-type $\mathrm{Ca}(2$ $+)$-activated potassium channels a viable target for the treatment of epilepsy? Expert Opin Ther Targets. 2015;19:911-26.

12. Schousboe A, Wellendorph $P$, Frolund $B$, Clausen RP, Krogsgaard-Larsen $P$. Astrocytic GABA Transporters: Pharmacological Properties and Targets for Antiepileptic Drugs. Adv Neurobiol. 2017;16:283-96.
13. Brodie MJ, Covanis A, Gil-Nagel A, Lerche H, Perucca E, Sills GJ, et al. Antiepileptic drug therapy: does mechanism of action matter? Epilepsy Behav. 2011;21: 331-41.

14. Ikemoto $Y$, Yamashita $M$, Yano $T$. Volatile anesthetics and a volatile convulsant differentially affect $G A B A(A)$ receptor-chloride channel complex. Toxicol Lett. 1998;100-101:225-31.

15. Martin DC, Abraham JE, Plagenhoef M, Aronstam RS. Volatile anesthetics and NMDA receptors. Enflurane inhibition of glutamate-stimulated [3H]MK-801 binding and reversal by glycine. Neurosci Lett. 1991;132:73-6.

16. Joseph JD, Peng Y, Mak DO, Cheung KH, Vais H, Foskett JK, et al. General anesthetic isoflurane modulates inositol 1,4,5-trisphosphate receptor calcium channel opening. Anesthesiology. 2014;121:528-37.

17. Kamatchi GL, Tiwari SN, Durieux ME, Lynch C 3rd. Effects of volatile anesthetics on the direct and indirect protein kinase C-mediated enhancement of alpha1Etype $\mathrm{Ca}(2+)$ current in Xenopus oocytes. J Pharmacol Exp Ther. 2000;293: $360-9$.

18. Herold KF, Sanford RL, Lee W, Schultz MF, Ingolfsson HI, Andersen OS, et al. Volatile anesthetics inhibit sodium channels without altering bulk lipid bilayer properties. J Gen Physiol. 2014;144:545-60.

19. Magyar J, Szabo G. Effects of volatile anesthetics on the $G$ protein-regulated muscarinic potassium channel. Mol Pharmacol. 1996;50:1520-8.

20. Kaisti KK, Langsjo JW, Aalto $S$, Oikonen V, Sipila $H$, Teras $M$, et al. Effects of sevoflurane, propofol, and adjunct nitrous oxide on regional cerebral blood flow, oxygen consumption, and blood volume in humans. Anesthesiology. 2003;99:03-13.

21. Bazzigaluppi P, Ebrahim AA, Weisspapir I, Stefanovic B, Carlen PL. Hungry neurons: metabolic insights on seizure dynamics. Int J Mol Sci. 2017;18 2269-82.

22. Miller RD, Cohen NH, Eriksson LI, Fleisher LA, Wiener-Kronish JP, Young WL. Miller's anesthesia. Philadelphia, PA: Elsevier/Saunders; 2015. 